\title{
Expression of Caspase-1 in breast cancer tissues and its effects on cell proliferation, apoptosis and invasion
}

\author{
YANXIA SUN and YINGZHEN GUO \\ Department of Galactophore, The First People's Hospital of Xinxiang, Xinxiang, Henan 453000, P.R. China
}

Received October 2, 2016; Accepted February 1, 2018

DOI: $10.3892 / \mathrm{ol} .2018 .8176$

\begin{abstract}
The present study aimed to detect the expression of Caspase-1 in the tumor tissues and tumor-adjacent tissues of patients with breast cancer, and to investigate the effects of Caspase-1 on the proliferation, apoptosis and invasion of breast cancer cells. Reverse transcription-quantitative polymerase chain reaction was used to detect Caspase-1 mRNA expression in breast cancer tissues and tumor-adjacent tissues from patients. Additionally, the human breast cancer MDA-MB-231 cell line was treated with the Caspase-1 small molecule inhibitor Ac-YVAD-CMK, following which the changes to Caspase-1 protein expression were detected via western blotting. The MTT method detected the changes to cell proliferation, flow cytometry detected the rate of apoptosis, and a Transwell assay was employed to assess invasion. Caspase-1 mRNA expression was significantly decreased in the breast cancer tissues of patients, compared with in the tumor-adjacent tissues, a difference that was statistically significant $(\mathrm{P}<0.05)$. Treatment with the Ac-YVAD-CMK markedly decreased the protein expression of Caspase-1 in MDA-MB-231 cells, and the difference was statistically significant $(\mathrm{P}<0.05)$. Following this treatment of Ac-YVAD-CMK cells, the proliferation and invasion abilities markedly increased, while the apoptotic levels significantly decreased $(\mathrm{P}<0.05)$. In conclusion, the expression of Caspase- 1 is low in breast cancer tissues, which may promote the proliferation and invasion of breast cancer cells and could be closely associated with the occurrence and development of breast cancer.
\end{abstract}

\section{Introduction}

Breast cancer is a common malignant tumor that presents a serious threat to female health. The incidence of breast cancer has increased in China in recent decades, and the age of onset has decreased $(1,2)$. The development of breast

Correspondence to: Dr Yanxia Sun, Department of Galactophore, The First People's Hospital of Xinxiang, 63 Yiheng Street, Xinxiang, Henan 453000, P.R. China

E-mail: yanxiasuncn@163.com

Key words: caspase-1, breast cancer, proliferation, apoptosis, invasion cancer is complex, and the specific underlying mechanisms remain to be elucidated. Previous studies have indicated that the inhibition of cellular apoptosis is closely associated with the occurrence and development of breast cancer $(3,4)$. The cysteine proteinase (Caspase) family serves an important role in the signaling pathways of cellular apoptosis (5). Interleukin (IL)- $1 \beta$ transferase (ICE; Caspase-1) is one of the Caspase family members. Previous studies have demonstrated that Caspase- 1 primarily activates IL-1 $\beta$, with little effect on cellular apoptosis (6). However, other studies have identified that the overexpression of Caspase-1 may induce cellular apoptosis, while the silencing of Caspase-1 may confer a tumor growth advantage $(7,8)$. Clinical studies have indicated that the expression of Caspase- 1 is decreased in a number of tumor tissues, including ovarian, prostate and colon cancer $(9,10)$. However, the function of Caspase-1 in the development of breast cancer remains unclear. In the present study, reverse transcription-quantitative polymerase chain reaction (RT-qPCR) was used to detect the expression of Caspase-1 mRNA in breast cancer and tumor-adjacent tissues, while the effects of the Caspase-1 small molecule inhibitor Ac-YVAD-CMK on the proliferation, apoptosis and invasion of breast cancer cells were detected, in order to investigate correlations between the expression and the occurrence and development of breast cancer.

\section{Subjects and methods}

Clinical data. All patients were treated in Department of Galactophore, the First People's Hospital of Xinxiang (Xinxiang, China) between January 2015 and January 2016. All tissue specimens were obtained from female patients who underwent the surgical removal of tumors and were pathologically diagnosed with primary breast cancer under a fluorescence microscope (magnification, x40; Olympus AX80; Olympus Corporation, Tokyo, Japan). The breast cancer tissues and corresponding tumor-adjacent tissues were removed and stored at $-80^{\circ} \mathrm{C}$ for later use. A total of 30 cases were selected, with ages ranging from 36 to 65 years (median ages, 50.18 \pm 8.42 years). All cases had not undergone chemo- or radiotherapy prior to surgery. The present study was conducted in accordance with the Declaration of Helsinki (2013 version), and with approval from the Ethics Committee of The First People's Hospital of Xinxiang. Written informed consent was obtained from all participants. 
Extraction of total RNA and RT-qPCR detection. A total of $100 \mathrm{~g}$ tissues were obtained from each specimen; $1 \mathrm{ml} \mathrm{TRIzol}{ }^{\circledR}$ (Invitrogen; Thermo Fisher Scientific, Inc., Waltham, MA, USA) was added and mixed with tissue homogenizer (PRO-200; Proscientific, Inc., Oxford, CT, USA), following which the total RNA was extracted using TRIzol reagent, according to the manufacturer's protocol (Invitrogen; Thermo Fisher Scientific, Inc.). The total RNA concentration and purity was detected using a UV spectrophotometer (Thermo Fisher Scientific, Inc.), and reverse transcription was conducted using a PrimeScript RT reagent kit (Invitrogen; Thermo Fisher Scientific, Inc.); the synthesized cDNA product was stored at $-20^{\circ} \mathrm{C}$ for later use. The primer sequences for RT-qPCR (Yingjun Co., Shanghai, China) are listed in Table I. GAPDH was used as a reference gene. An RT-qPCR system (ABI PRISM ${ }^{\circledR}$ 7300; Applied Biosystems, Foster City, CA, USA) was used to detect the expression of Caspase-1 mRNA. The total RT-qPCR amplification reaction volume was $25 \mu \mathrm{l}$ and the thermocycler conditions were as follows: $50^{\circ} \mathrm{C}$ for $2 \mathrm{~min}$, then $95^{\circ} \mathrm{C} \mathrm{Taq}$ enzyme activation for $10 \mathrm{~min}$, followed by $95^{\circ} \mathrm{C}$ for $15 \mathrm{sec}$ and then $60^{\circ} \mathrm{C}$ for $1 \mathrm{~min}$, for 40 cycles. The $2^{-\Delta \Delta \mathrm{Cq}}$ method was utilized to demonstrate relative expression (11).

Western blotting. MDA-MB-231 cells (Cell Bank of Chinese Academy of Sciences, Shanghai, China) were cultured in RPMI-1640 medium (Hyclone; GE Healthcare, Chicago, IL, USA) supplemented with $10 \%$ fetal bovine serum (FBS; Si Ji Qing, Hangzhou, China) and incubated at $37^{\circ} \mathrm{C}$ in $5 \%$ $\mathrm{CO}_{2}$, and with Ac-YVAD-CMK at different final concentrations $(0,5,10,20$ and $30 \mu \mathrm{mol} / \mathrm{l}$; Bachem AG, Bubendorf, Switzerland) for $48 \mathrm{~h}$; following trypsinization, the cells were collected; total protein samples were extracted using radioimmunoprecipitation assay lysis buffer and the protein concentration was detected using a BCA protein quantitative reagent kit (Thermo Fisher Scientific, Inc.). The proteins (100 ng protein per lane) were separated via 10\% SDS-PAGE, transferred to a polyvinylidene fluoride membrane using a wet chemistry method (12), and agitated with 5\% dried skimmed milk at room temperature and blocked for $2 \mathrm{~h}$; the membrane was washed thrice with TBS-T and then incubated with a Caspase-1 antibody (catalog no. 2225S; dilution, 1:1,000; Cell Signaling Technology, Inc., Danvers, MA, USA) or a $\beta$-actin antibody (catalog no. BM0627; dilution, 1:300; Wuhan Boster Biological Technology, Ltd., Wuhan, China) at $4^{\circ} \mathrm{C}$ overnight. Subsequent to washing with TBS-T, the membranes were incubated with a horseradish peroxidase-conjugated goat anti-rabbit secondary antibody (catalog no. GA1014; dilution, 1:5,000; Wuhan Boster Biological Technology, Ltd.) at room temperature for $1 \mathrm{~h}$; following this, ECL solution (EMD Millipore, Billerica, MA, USA) was used for chemical luminescence, and the EC3 Imaging System (UVP, Inc., Upland, CA, USA) was used to visualize the protein bands, quantified by grey level analysis using Image $\mathrm{J}$ software (National Institutes of Health, Bethesda, MD, USA). The experiment was repeated three times.

MTT assay. MDA-MB-231 cells were cultured in L-15 medium (Hyclone; GE Healthcare, Chicago, IL, USA) (containing 10\% fetal bovine serum, $100 \mathrm{U} / \mathrm{ml}$ penicillin and
$100 \mathrm{U} / \mathrm{ml}$ streptomycin); the MDA-MB-231 cells at the logarithmic growth phase were digested, and then inoculated into 96-well plate at $100 \mu \mathrm{l} /$ well (containing $\sim 1 \times 10^{4}$ cells) for $24 \mathrm{~h}$. A total of 6 parallel wells were set for the Ac-YVAD-CMK group (final concentration, $10 \mu \mathrm{mol} / \mathrm{l}$ ) and the control group [dimethyl sulfoxide (DMSO)]. After 24, 48 and $72 \mathrm{~h}$ of culturing, $50 \mu \mathrm{l} 1 \mathrm{X}$ MTT solution was added into each well and cultured for $4 \mathrm{~h}$ in an incubator at $37^{\circ} \mathrm{C}$. The supernatant was removed, and $150 \mu 1$ DMSO was added into each well, following which the contents were agitated using a plate shaker. The absorbance [optical density (OD)] value of each well was detected at a wavelength of $490 \mathrm{~nm}$ using a microplate reader (CliniBio, Eugendorf, Austria); the OD values represent the relative proliferation level of the cells. The experiment was repeated three times.

Cell apoptosis experiment. MDA-MB-231 cells were inoculated into 6 -well plates $\left(1 \times 10^{6}\right.$ cells/well $)$. When its confluence was $60 \%$, the Ac-YVAD-CMK (final concentration, $10 \mu \mathrm{mol} / \mathrm{l}$ ) and control (DMSO) were added. Three parallel wells were selected for each group. After $24 \mathrm{~h}$ of culturing, the cells were digested using $0.25 \%$ trypsin (Gibco; Thermo Fisher Scientific, Inc.) and collected, following the protocol of the Annexin V-fluorescein isothiocyanate (FITC)/propidium iodide (PI) apoptosis detection kit (Kaiji Biotech Co., Nanjing, China). The cells were suspended in $500 \mu \mathrm{l}$ Binding Buffer prior to the addition of $5 \mu \mathrm{l}$ Annexin V-FITC. Subsequently, $5 \mu \mathrm{l}$ PI was added and the mixture was incubated for $10 \mathrm{~min}$ in the dark, following which the apoptotic cells were detected using flow cytometry (FACSCalibur ${ }^{\mathrm{TM}}$; BD Biosciences, Franklin Lakes, NJ, USA), The apoptotic rate was calculated according to the proportions of cells in the upper and lower right-hand quadrants. The experiment was repeated three times.

Transwell cell invasion experiment. The Transwell inserts were coated with $100 \mu \mathrm{l}$ Matrigel and irradiated with UV at $20 \mathrm{~Gy}$ for $2 \mathrm{~h}$. The MDA-MB-231 cells pretreated with Ac-YVAD-CMK $(10 \mu \mathrm{mol} / \mathrm{l})$ were trypsinized, and the cell density was calculated. The cells were seeded into the upper Transwell chambers at $100 \mu \mathrm{l} /$ well ( $\sim 1 \times 10^{5}$ cells), and $500 \mu \mathrm{l}$ L-15 medium containing $10 \%$ fetal bovine serum was added into the lower chambers. After $24 \mathrm{~h}$ of culturing, the Transwell insert was removed and washed with PBS; the cells in the upper layer was removed with a cotton bud and fixed with $95 \%$ ethanol at $37^{\circ} \mathrm{C}$ for $1 \mathrm{~h}$, prior to staining with $4 \mathrm{~g} / 1$ Trypan Blue solution. Using an inverted microscope (magnification, x40; TS100; Nikon, Tokyo, Japan), the cells penetrating the membrane in 10 randomly selected fields of view were counted. The experiment was repeated three times.

Statistical analysis. SPSS 20.0 software (IBM Corp., Armonk, NY, USA) was used for statistical analysis. The observation data were normally distributed. Comparisons between two groups were performed using a paired t-test, and comparisons between more than two groups were conducted using a one-way analysis of variance and a pair-group Least Significant Difference test. $\mathrm{P}<0.05$ was considered to indicate a statistically significant difference 
Table I. Primer sequences for reverse transcription-quantitative polymerase chain reaction.

\begin{tabular}{lc}
\hline Gene & Primer sequence (5'-3') \\
\hline Caspase-1 & \\
Forward & TTTCCGCAAGGTTCGATTTTCA \\
Reverse & GGCATCTGCGCTCTACCATC \\
GAPDH & \\
Forward & GGAGCGAGATCCCTCCAAAAT \\
Reverse & GGCTGTTGTCATACTTCTCATGG \\
\hline
\end{tabular}

Table II. mRNA expression of miRNA-204 in breast cancer and tumor-adjacent tissues.

\begin{tabular}{lccc}
\hline Group & $\begin{array}{c}\text { mRNA of } \\
\text { Caspase-1 }\left(2^{-\Delta \Delta C q}\right)\end{array}$ & t & P-value \\
\hline Breast cancer tissues & $2.14 \pm 0.93$ & 9.842 & $<0.000001$ \\
Tumor-adjacent tissues & $4.62 \pm 1.02$ & & \\
\hline
\end{tabular}

t, Student's t-test.

\section{Results}

Comparison of Caspase-1 mRNA expression in breast cancer and tumor-adjacent tissues. RT-qPCR detected the expression of Caspase-1 mRNA in breast cancer and tumor-adjacent tissues obtained from patients. Compared with the corresponding tumor-adjacent tissues, the breast cancer tissues had significantly decreased expression of Caspase-1 mRNA, and the difference was statistically significant $(\mathrm{P}<0.05)$, which indicated that Caspase-1 may serve a function during the development of breast cancer (Table II).

Ac-YVAD-CMK inhibits Caspase-1 protein expression. Using western blotting, Caspase-1 protein expression was detected in the MDA-MB-231 cells following treatment with Ac-YVAD-CMK at various final concentrations. The results indicated that Ac-YVAD-CMK may inhibit Caspase-1 protein expression; as the Ac-YVAD-CMK concentration increased, the expression of Caspase-1 decreased; the gray level analysis indicated statistical significance $(\mathrm{P}<0.05$; Fig. 1).

Effects of the inhibition of Caspase-1 protein expression on proliferation ability. An MTT assay was used to detect the changes in MDA-MB-231 cell proliferation following treatment with $10 \mu \mathrm{mol} / 1$ Ac-YVAD-CMK for 24, 48 and 72 h. Compared with the control group, the MDA-MB-231 cells treated with Ac-YVAD-CMK exhibited significantly increased proliferation ability, in a time-dependent manner ( $\mathrm{P}<0.05$; Fig. 2).

Effects of the inhibition of Caspase-1 protein expression on apoptosis. MDA-MB-231 cells were treated with Ac-YVAD-CMK (final concentration, $10 \mu \mathrm{mol} / \mathrm{l}$ ) for $24 \mathrm{~h}$,
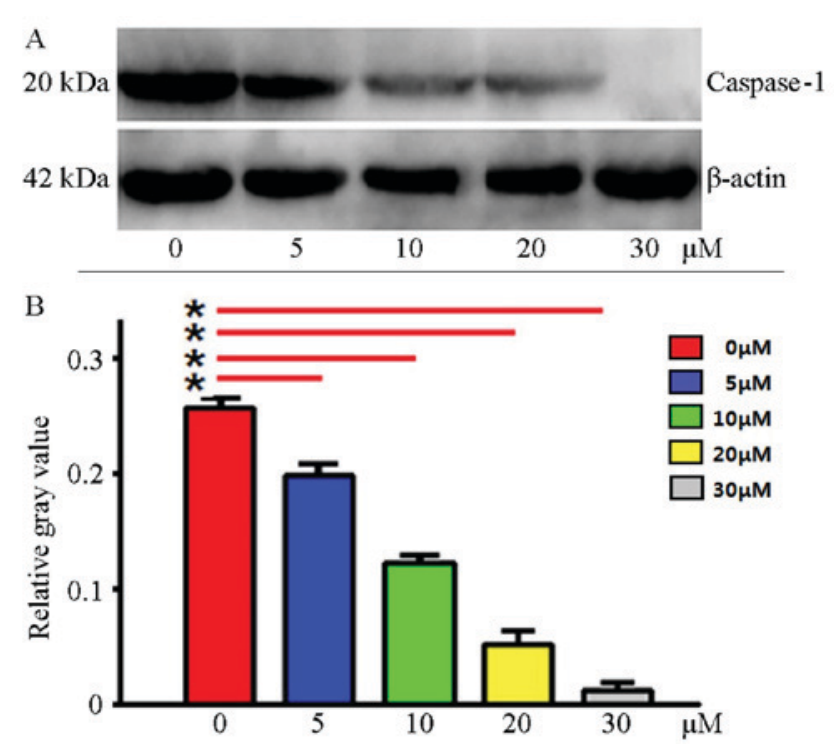

Figure 1. Ac-YVAD-CMK inhibits Caspase-1 protein expression. (A) Representative image of the western blots. (B) The gray level analysis results for western blotting. The results indicated that Ac-YVAD-CMK cells could inhibit Caspase-1 protein expression. As the Ac-YVAD-CMK concentration increased, the expression of Caspase-1 decreased gradually. ${ }^{*} \mathrm{P}<0.05$ vs. blank control $(0 \mu \mathrm{M})$.

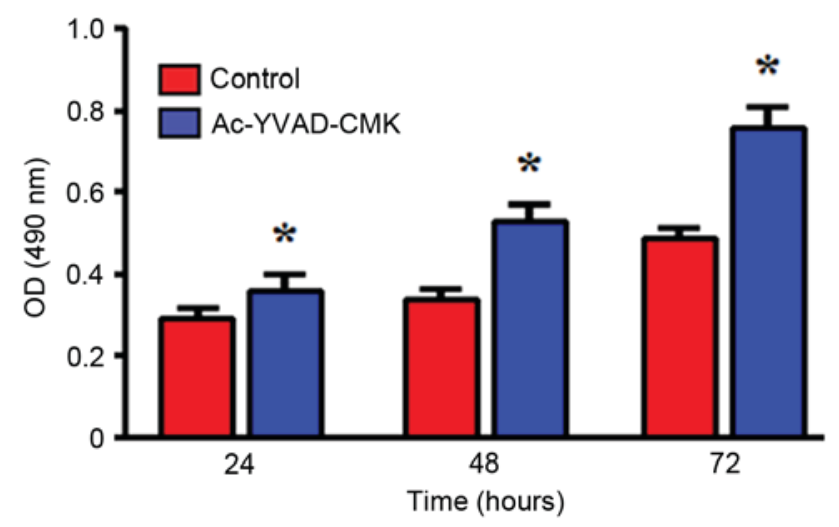

Figure 2. Effect of Caspase-1 protein inhibition on proliferation ability. ${ }^{*} \mathrm{P}<0.05$ vs. control $(0 \mu \mathrm{M})$. OD, optical density. Compared with the control group, the MDA-MB-231 cells affected by Ac-YVAD-CMK had obviously increasing proliferation ability which growed with time.

and then the apoptotic levels were detected with flow cytometry. The results indicated that the apoptotic proportion of MDA-MB-231 cells in the Ac-YVAD-CMK group was markedly decreased compared with that of the control group, and that this difference was statistically significant $(\mathrm{P}<0.05$; Fig. 3).

Effects of the inhibition of Caspase-1 protein expression on cell invasion. MDA-MB-231 cells were treated with Ac-YVAD-CMK (final concentration, $10 \mu \mathrm{mol} / \mathrm{l}$ ) for $24 \mathrm{~h}$, and then the invasion ability in vitro was detected with a Transwell assay. The results indicated that the number of MDA-MB-231 cells that penetrated the upper chamber layer in the Ac-YVAD-CMK group was significantly increased, compared with in the control group, a difference that was statistically significant $(\mathrm{P}<0.05$; Fig. 4). 

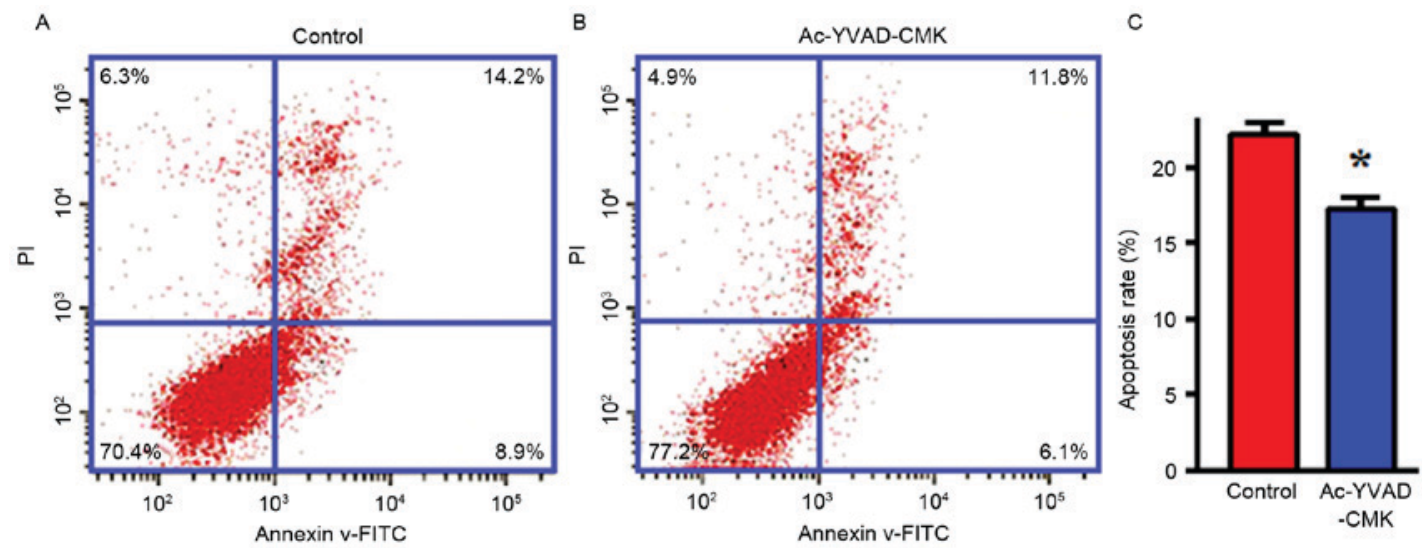

Figure 3. Effect of Caspase-1 protein inhibition on apoptosis. (A) Control and (B) Ac-YVAD-CMK groups. (C) Comparison between the two groups. "P<0.05 vs. blank control $(0 \mu \mathrm{M})$. PI, propidium iodide; FITC, fluorescein isothiocyanate. The apoptotic proportion of MDA-MB-231 cells in the Ac-YVAD-CMK group was reduced compared with that of the control group.
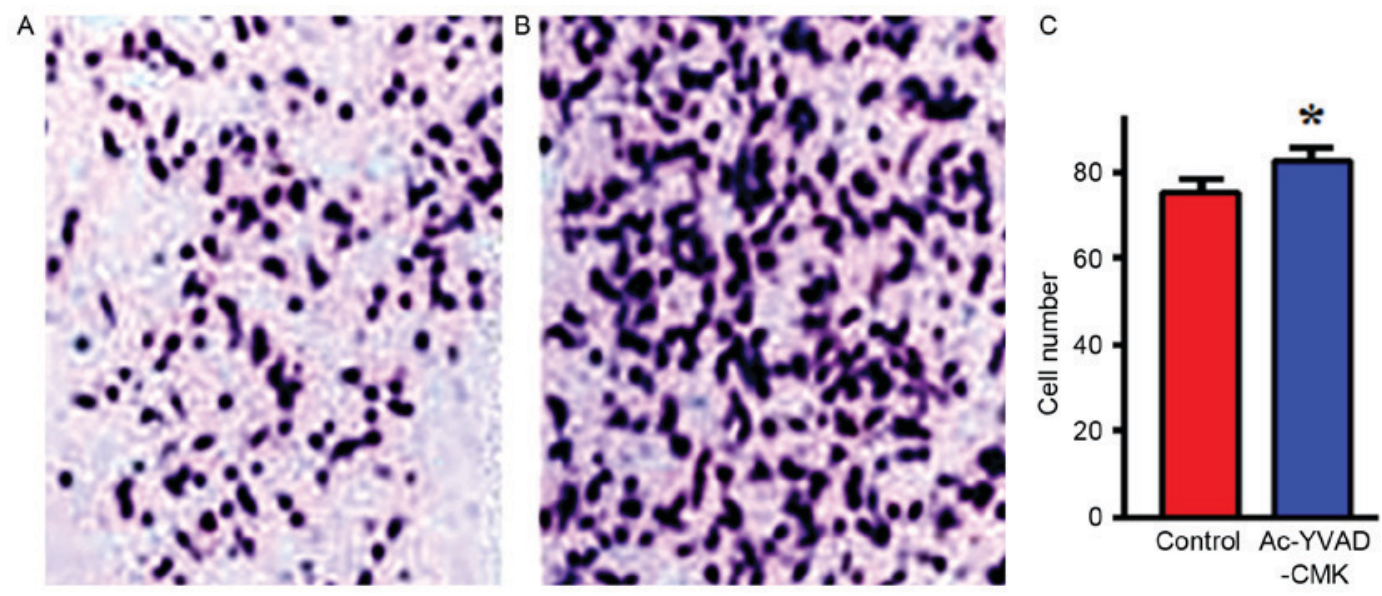

Figure 4. Effect of Caspase-1 protein inhibition on invasion ability. " $\mathrm{P}<0.05$ vs. blank control $(0 \mu \mathrm{M})$. (A) Staining of the control group (magnification, 40 ). (B) Staining $f$ the Ac-YVAD-CMK group (magnification, $\mathrm{x} 40$ ). (C) Comparison of invasion ability between 2 groups.

\section{Discussion}

Among the female-specific cancer types, breast cancer highest associated cause of mortality in developing countries (13). In China, breast cancer accounts for $\sim 12.2 \%$ of global cases per year, while the associated mortalities account for $~ 9.6 \%$ (14). Breast cancer is a complex heterogeneous tumor, involving numerous factors during its occurrence and development, but the specific mechanisms remain unclear. Previous studies have hypothesized that the occurrence and development of breast cancer is closely correlated with the inhibition of apoptosis (3).

Apoptosis is the process of programmed cell death, controlled by genes, so as to maintain a stable internal environment, which involves the activation, expression and regulation of a series of genes (15). The Caspase family is the major executor of apoptotic cytoclasis, and serves important functions during the apoptotic process $(16,17)$. Caspase- 1 is a member of the Caspase family, and was the first to be identified (18). As the typical inflammation-associated Caspase, Caspase-1 is a key effector molecule during the inflammatory response, regulating the inflammatory reaction in the tumor microenvironment and the anti-tumor immunity of organisms $(19,20)$. Recent studies demonstrated that Caspase-1 functions in apoptosis $(21,22)$. $\mathrm{Hu}$ et al (23) identified that the formation of tumors in Caspase-1-deficient (Casp1 (-/-) mice was increased, and that Caspase-1 affects tumorigenesis not by regulating colon inflammation, but by regulating the colon epithelial cell proliferation and apoptosis. Chen et al (24) injected 4T1 cells into the mammary fat pads of mice to establish a xenograft model of breast cancer; on this basis, they introduced the Caspase-1 specific-inhibitor Ac-YVAD-CMK via intraperitoneal injection into tumor-bearing mice, and identified that Ac-YVAD-CMK may increase the tumor weight and splenomegaly, demonstrating that Caspase-1 may inhibit tumor development by regulating the development of MDSCs in peripheral tissues (peripheral blood, spleen) and in the tumor microenvironment.

Based on these previous studies, the present study analyzed whether Caspase-1 is involved in the occurrence and development of breast cancer by regulating the proliferation and apoptosis of breast cancer cells. Firstly, the expression of Caspase-1 mRNA in breast cancer tissues and tumor-adjacent tissues was detected. It was identified that the expression of Caspase-1 in breast cancer tissues was significantly decreased compared with in tumor-adjacent tissues, 
which is consistent data from a study examining prostatic cancer by Veeranki (25). It suggests that low expression levels of Caspase-1 may, to a certain degree, function in promoting the occurrence and development of breast cancer. Following this, the Caspase-1 small molecule inhibitor Ac-YVAD-CMK was used to treat MDA-MB-231 cells in order to decrease the expression of Caspase-1, and then the cell biological function of MDA-MB-231 was detected. The experimental results demonstrated that the proliferation and invasion abilities of cells were markedly increased, while the apoptotic levels were significantly decreased compared with the controls, which may potentially promote the development of breast cancer.

In summary, the low expression levels of Caspase-1 serve a vital role in the occurrence and development of breast cancer, and affect the proliferation, apoptosis and invasion of breast cancer cells. Thus, Caspase-1 may be a novel target molecule for treating breast cancer, representing a novel avenue for the exploitation of drugs used to treat these tumors.

\section{Competing interests}

The authors declare that they have no competing interests.

\section{References}

1. Song QK, Wang XL, Zhou XN, Yang HB, Li YC, Wu JP, Ren J and Lyerly HK: Breast cancer challenges and screening in China: Lessons from current registry data and population screening studies. Oncologist 20: 773-779, 2015.

2. Song QK, Li J, Huang R, Fan JH, Zheng RS, Zhang BN, Zhang B, Tang ZH, Xie XM, Yang HJ, et al: Age of diagnosis of breast cancer in China: Almost 10 years earlier than in the United States and the European union. Asian Pac J Cancer Prev 15: 10021-10025, 2014.

3. Jordan VC: The new biology of estrogen-induced apoptosis applied to treat and prevent breast cancer. Endocr Relat Cancer 22: R1-R31, 2015.

4. Wang Q, Du X, Zhou B, Li J, Lu W, Chen Q and Gao J: Mitochondrial dysfunction is responsible for fatty acid synthase inhibition-induced apoptosis in breast cancer cells by PdpaMn. Biomed Pharmacother 96: 396-403, 2017.

5. Galluzzi L, Lopez-Soto A, Kumar S and Kroemer G: Caspases connect cell-death signaling to organismal homeostasis. Immunity 44: 221-231, 2016.

6. Winkler S and Rösen-Wolff A: Caspase-1: An integral regulator of innate immunity. Semin Immunopathol 37: 419-427, 2015.

7. Sagulenko V, Vitak N, Vajjhala PR, Vince JE and Stacey KJ: Caspase-1 is an apical caspase leading to caspase-3 cleavage in the AIM2 inflammasome response, independent of caspase- 8 J Mol Biol 430: 238-247, 2018.

8. Mascarenhas DPA, Cerqueira DM, Pereira MSF, Castanheira FVS, Fernandes TD, Manin GZ, Cunha LD and Zamboni DS: Inhibition of caspase-1 or gasdermin-D enable caspase-8 activation in the Naip5/NLRC4/ASC inflammasome. PLoS Pathog 13: e1006502, 2017.
9. Shalini S, Dorstyn L, Dawar S and Kumar S: Old, new and emerging functions of caspases. Cell Death Differ 22: 526-539, 2015.

10. Nunes T and de Souza HS: Inflammasome in intestinal inflammation and cancer. Mediators Inflamm 2013: 654963, 2013.

11. Livak KJ and Schmittgen TD: Analysis of relative gene expression data using real time quantitative PCR and the 2(-Delta Delta C(T)) method. Methods 25: 402-408, 2001.

12. Ericsson $\mathrm{C}$ and Nistér M: Protein extraction from solid tissue. Methods Mol Biol 675: 307-312, 2011.

13. da Costa Vieira RA, Biller G, Uemura G, Ruiz CA and Curado MP: Breast cancer screening in developing countries. Clinics (Sao Paulo) 72: 244-253, 2017.

14. Fan L, Strasser-Weippl K, Li JJ, St Louis J, Finkelstein DM, Yu KD, Chen WQ, Shao ZM and Goss PE: Breast cancer in China. Lancet Oncol 15: e279-e289, 2014.

15. Eroglu MandDerry WB: Yourneighboursmatter-non-autonomous control of apoptosis in development and disease. Cell Death Differ 23: 1110-1118, 2016.

16. Man SM and Kanneganti TD: Converging roles of caspases in inflammasome activation, cell death and innate immunity. Nat Rev Immunol 16: 7-21, 2016.

17. Adamiec-Mroczek J, Zajac-Pytrus H and Misiuk-Hojlo M: Caspase-dependent apoptosis of retinal ganglion cells during the development of diabetic retinopathy. Adv Clin Exp Med 24: 531-535, 2015.

18. Martinon F and Tschopp J: Inflammatory caspases and inflammasomes: Master switches of inflammation. Cell Death Differ 14: 10-22, 2007.

19. Guey B and Petrilli V: Assessing Caspase-1 activation. Methods Mol Biol 1417: 197-206, 2016.

20. Winkler S, Hedrich CM and Rösen-Wolff A: Caspase-1 als regulates der autoinflammation bei rheumatischen Erkrankungen. Z Rheumatol 75: 265-275, 2016.

21. Sollberger G, Strittmatter GE, Grossi S, Garstkiewicz M, Auf dem Keller U, French LE and Beer HD: Caspase-1 activity is required for UVB-induced apoptosis of human keratinocytes. J Invest Dermatol 135: 1395-1404, 2015.

22. Xi H, Zhang Y, Xu Y, Yang WY, Jiang X, Sha X, Cheng X, Wang J, Qin X, Yu J, et al: Caspase-1 inflammasome activation mediates Homocysteine-induced Pyrop-apoptosis in endothelial cells. Circ Res 118: 1525-1539, 2016.

23. Hu B, Elinav E, Huber S, Booth CJ, Strowig T, Jin C, Eisenbarth SC and Flavell RA: Inflammation-induced tumorigenesis in the colon is regulated by caspase-1 and NLRC4. Proc Natl Acad Sci USA 107: 21635-21640, 2010.

24. Chen YJ, Zheng W, Niu ZY, Wu Z and Shen PP: Caspase-1modulates breast cancer growth and the development of myeloid-derived suppressor cells. Chin J Immun 29: 1128-1134, 2013.

25. Veeranki S: Role of inflammasomes and their regulators in prostate cancer initiation, progression and metastasis. Cell Mol Biol Lett 18: 355-367, 2013.

This work is licensed under a Creative Commons Attribution-NonCommercial-NoDerivatives 4.0 International (CC BY-NC-ND 4.0) License. 